\title{
A saúde entre o minoritário e o global: questões identitárias entre mulheres quilombolas
}

\author{
The health between the minority and the global: identity issues between quilombolas \\ women
}

\author{
Renata Patricia Forain de Valentim ${ }^{1}$
}

\begin{abstract}
RESUMO: Esta pesquisa teve por objetivo, através da técnica dos grupos focais, investigar a relação entre representações, memórias e práticas relativas à saúde e as autodefinições identitárias entre um grupo de mulheres quilombolas. A suposição inicial foi a de que estas memórias e representações funcionariam como um elemento de resistência e cumpririam uma função social, como constituição e posicionamento de formas identitárias frente às formas massificadamente tecnificadas, globais e culturalmente indiferenciadas, que chegaram à região a partir da última metade do século XX. A hipótese, neste caso, seria a de que recordar e resistir se tornariam muito próximos, funcionando como elementos representacionais, frutos de uma composição que precisou ser reconstituída em suas práticas de pertencenimento e de atuação.
\end{abstract}

Palavras-chave: identidade; comunidades tradicionais; globalização; quilombolas.

\begin{abstract}
This research aimed, through the technique of focus groups, to investigate the relationship between representations, memories and practices relating to health and self-definitions of identity among a group of women quilombolas. The initial assumption was that these memories and representations function as an element of strength and fulfill a social function, mainly related to identity issues and their relationship to ways forward technicality, global and culturally undifferentiated, who arrived in the region from the last half of the twentieth century. The hypothesis in this case, would be that the remember and resist become very closed, working as representational elements, fruits of a composition that had to be reconstituted in their practices pertencenimento and action.
\end{abstract}

Keywords: identity; traditional communities; globalization; quilombolas.

\section{Introdução}

A posição de proximidade e distanciamento, sedução e aversão, das diversas identidades culturais frente às inovações trazidas pela modernidade é o tema que fixa o campo inicial deste trabalho. Hibridismo definido pelo que Santiago (1978) vai denominar de "entrelugar" discursivo: áreas de encontro (e de conflito) entre as diferentes formas narrativas que compõem um território cultural e social em mutação, nas quais as questões acerca da identidade cultural, vão ocupar um lugar privilegiado de questionamento.

A oportunidade de realizar a pesquisa sobre estes lugares e seu processo de resignificação surgiu do contato com comunidades remanescentes de quilombos, localizadas ao norte do estado do Espírito Santo, em uma região conhecida como Sapê do Norte. Esta região, que abriga atualmente os municípios de Conceição da Barra e São Mateus, foi no passado um importante polo do regime escravagista, sendo o porto de São Mateus um dos mais importantes pontos de chegada e distribuição de escravos para as fazendas de cana de açúcar e café do estado. (Novaes, n.d.)

\footnotetext{
${ }^{1}$ Doutora em psicologia pela Universidade Federal do Espírito Santo; Docente do departamento de Psicologia Social e Institucional da Universidade do Estado do Rio de Janeiro - Rio de Janeiro, RJ, Brasil. E-mail: renatapfvalentim@gmail.com.
} 
Este litígio de inserções, valores e culturas que se dá localmente nas comunidades analisadas, acontece em circunstâncias paradigmáticas de um movimento contemporâneo mais geral. Neste movimento, estas formas tecnocráticas e ocidentais, urbanas e globais, características da modernidade, passam a ser contrapostas a novas formas de identificações coletivas: negros, mulheres, indígenas, pacifistas, religiosos, etc; que vão colocar em questão sua predominância e impor uma leitura diferenciada de seus processos. Segundo Burity (2001), esta busca de descentramento e de uma afirmação identitária grupal singularizada seria proporcional às investidas cada vez mais predominantes de uma ordem social mercadológica e tecnocrática, institucionalizada no atual sistema de estados nacionais, que necessariamente se faz acompanhar por uma "potencialização da demanda por singularidade e espaço para a diferença e o localismo" (Burity, 2001, p. 2; Bhabha, 2001).

Neste caso específico, o território analisado tem sido desde as últimas décadas do século XX alvo de radicais transformações, demarcadas a partir da instalação do maior complexo agroindustrial de celulose do planeta e de toda a infraestrutura que o acompanha e alimenta. Para tanto, além dos extensos plantios de eucalipto que abastecem as fábricas de matéria-prima, neste período foram construídas estradas e rodovias para o escoamento da produção, bairros criados para abrigar funcionários, incluindo ainda os investimentos e empreendimentos do estado em saneamento, saúde e educação básicos. (Arruti, 2005)

Historicamente, de formas mais ou menos violentas, as comunidades remanescentes foram sendo paulatinamente expulsas da região. Sem opções de trabalho após a derrubada da mata e com exíguas porções de terra para a agricultura, as cerca de 12 mil famílias que habitavam a região até 1967, ano da inauguração da primeira fábrica, estão hoje reduzidas a 1.200 famílias. Plantam o mínimo, insuficiente para a subsistência; dedicam-se à produção do carvão a partir dos resíduos do eucalipto ou estão subempregadas em empresas terceirizadas, que prestam serviços às fábricas (Arruti, 2005; Novaes, n.d.).

O conjunto destas comunidades é variado. Existem desde as mais recolhidas, encravadas em meio a quilômetros ininterruptos da monocultura de eucalipto; até aquelas localizadas na beira da BR-101 - importante via de ligação entre as regiões sudeste e nordeste do Brasil- e, portanto, muito mais suscetíveis ao intercâmbio com o meio urbano.

O grupo de mulheres denominado "Natureza em Ação" reúne-se mensalmente desde junho de 2007 e é composto por representantes de diversas comunidades. De modo sintomático, seu surgimento ocorre durante uma ocupação de terras e desde o início, sua formação se fez em torno das questões relacionadas à saúde e das formas de tratamento usadas tradicionalmente por estes remanescentes, principalmente pelas mulheres. Seus encontros são marcados sempre nas próprias comunidades e consistem tanto de atividades pragmáticas de mutirões de plantios, feitura de remédios e troca de mudas; como de discussões acerca de temas diversos relacionados principalmente às práticas ancestrais de religião, de cura e das formas de cultivo e uso das ervas medicinais.

O que motiva o estudo focal com este grupo de mulheres é o fato de que não seria possível tomar estas recuperações mnêmicas acerca da saúde, da religião ou do território apenas como fatos estáticos e finitos localizados em um passado determinado. A suposição foi a de que estas memórias funcionariam como um elemento de resistência e cumpririam uma função social, relacionada principalmente às questões identitárias e sua relação frente às formas massificadamente tecnificadas, globais e culturalmente indiferenciadas, que chegaram na região a partir da última metade do século XX. A hipótese, neste caso, seria a de que recordar e resistir se tornariam muito próximos, funcionando como elementos repre- 
sentacionais, frutos de uma composição que precisou ser reconstituída em suas práticas de pertencenimento e de atuação.

\section{O processo identitário: de fato social à construção psicossocial}

Embora não abordando diretamente a questão da identidade, em sua definição de "fato social", Durkheim (1985) postula a existência de uma "consistência", isolada dos acontecimentos particulares e distinta dos fatos individuais que a traduzem. Esta manifestação "sócio-psíquica", da qual as representações coletivas fazem parte, (Sá, 1993) não seria relevante apenas por ser geral, mas por desempenhar um "poder de coerção externa que exerce ou é suscetível de exercer sobre os indivíduos" (Durkheim, 1985, p. 8). Segundo Sá (1993), além deste poder de coerção o modelo de representação coletiva, tal como defendido por Durkheim, se caracterizaria ainda por estabelecer uma relação de total autonomia e exterioridade com relação ao sujeito que o traz: "(...) os indivíduos que compõem a sociedade seriam portadores e usuários das representações coletivas, mas estas não poderiam ser legitimamente reduzidas a algo como o conjunto das representações individuais, das quais difeririam inteiramente." (Sá, 1993, p. 21).

Partindo criticamente de muitos aspectos do método sociológico durkheimiano, Moscovici analisa os processos discursivos deste conhecimento elaborado em comum e apresenta outro modelo teórico de representação cognitiva do mundo: a teoria das representações sociais. Para o autor, o poder unificador destas representações, diferentemente do que supunha Durkheim, não precisaria se exercer de forma coercitiva ou unilateral. Estabelecidas através das narrativas quase sempre orais do senso comum, de suas definições e explicações da realidade, as representações sociais possuiriam um caráter pedagógico e formador das práticas sociais subjetivas nas quais "os conteúdos mentais são imperativos mais fortes que formas cognitivas" (Moscovici, 2004, p. 211).

Estas narrativas orais compreenderiam aquele universo definido por Moscovici como consensual, onde as configurações sociais e culturais não obedeceriam às formas científicas de difusão e compreensão, características do universo reificado; mas pertenceriam às formas cotidianas dos discursos comuns, construídas dentro de universos sociais específicos e relevantes para grupos sociais determinados.

Entretanto, diferentemente de Durkheim, Moscovici não supõe nestas narrativas uma forma fechada, "conformadas pelo núcleo mítico e ritual da tradição de um povo" (Moscovici, 2004, p. 195). Faz parte das representações do universo consensual, uma contínua negociação, característica dos "intercâmbios da vida cotidiana" (idem), onde os conteúdos do universo reificado circulam e progressivamente se contextualizam, tornando os processos identitários formas dinâmicas, em contínua transformação.

A força de coesão, neste caso, também não se faria de modo externo, mas sim em uma dinâmica de organização psicossocial que atua em dois níveis distintos, porém indissociáveis. No primeiro, os processos individuais, que permitem a atuação em sociedade e arranjam o modo pelo qual "os indivíduos organizam sua experiência com o meio ambiente" (Doise, 2002, p. 28). No segundo, o das dinâmicas sociais, "particularmente as interacionais, posicionais ou de valores e crenças gerais" (Doise, 2002, p. 28), que formam e orientam o funcionamento destes processos individuais. 
No caso das referências identitárias, a interação e dinâmica destes dois níveis fazem com que a análise do tema também se desdobre em dois planos: o primeiro seria o plano interno, o da coesão intragrupal, que envolve o processo psicológico subjetivo de pertencenimento e o do "sentir-se identificado" (Souza, 2005, p. 132). O segundo seria o plano das relações intergrupos, que, como já foi dito, envolve os processos de inclusão e exclusão, bem como a determinação de uma alteridade, de um "outro" que funcione como uma antítese necessária, utilizada para afirmação do idêntico.

A postulação de um "outro", de uma alteridade, toma relevo na discussão sobre os processos identitários em diversos autores sob diferentes ângulos. Também reiterando a importância de um "outro" para a tematização da própria identidade, Jovchelovitch (2002) afirma que, sem este reconhecimento e de seus correlatos não apenas a identidade, mas a própria forma simbólica de trocas culturais e a linguagem seriam inexistentes. Duveen (2002), indo ao encontro destas colocações, afirma ainda que a "relação da criança com o outro é a fonte para a atividade construtiva da criança na qual o eu e o outro surgem como objetos constituídos". (Duveen, 2002, p. 92).

Nestes, assim como em outros autores, a questão da identidade e da alteridade aparecem imbricadas no mesmo processo genético. Causador, ao mesmo tempo em que dependente da formação de atividades cognitivas básicas, este "outro" proporcionaria ao indivíduo sua localização, não apenas em termos de pertencenimento social, como também em termos de uma diferenciação geral em relação ao mundo.

Aprofundando este caráter formador da alteridade, Jodelet (2002) desdobra o conceito e o insere em duplo processo, onde poderiam ser distinguidas a alteridade do próximo, de "outrem", e a alteridade longínqua ou exótica de um "outro". (Jodelet, 2002, p. 48). Este desdobramento, segundo a autora, seria a condição fundamental para a compreensão de uma distinção feita pelos sujeitos entre um não-eu, semelhante e mediado pelas mesmas condições culturais, e uma alteridade radical, que se põe para além das projeções de "unidade do mesmo para consigo mesmo" (Jodelet, 2002, p. 55).

No campo delimitado, essa relação com a alteridade pode ser verificada no processo de mudanças que têm se originado nas últimas décadas entre estas populações tradicionais que habitavam o norte do ES. Neste período foram definidas desde novas formas aparentemente singulares de dar à luz, de sentir, habitar, vestir, até novas expressões e palavras para falar de coisas que não existiam originalmente em seus universos culturais. Nesse mesmo período as crianças passam a frequentar as escolas formais, chegam a luz e a televisão, a telefonia móvel. Na construção (individual e coletiva) deste novo léxico e desta nova sintaxe, a necessidade de transformar esta alteridade em algo "tangível". Processo múltiplo e emaranhado, que, segundo Moscovici (2004), atuaria tanto a nível inter ou intrapessoal _ modificando os mecanismos através dos quais os indivíduos se relacionam e processam as novas informações _ quanto a nível inter ou intragrupal, modificando as crenças e valores partilhados pela comunidade e suas relações com outros grupos.

Nestes desdobramentos circunscritos, a possibilidade de identificar uma contínua complexificação dos processos psicossociais identitários, dos quais passa a ser exigida uma reorganização contínua (absolutamente necessária à sobrevivência das comunidades remanescentes), que interconecte e atualize as formas tradicionais a outras formas culturais e sociais, tornando-as mais relevantes e recorrentes, justamente na medida em que se tornem 
mais permissíveis a estas recriações "transtemporais" (Campos, 1997, p. 258) ou "híbridas" (Bhabha, 2001, p.26).

No caso específico das comunidades analisadas, esta "modernidade" _ caracterizada, dentre outras formas, pela "contínua aceleração industrial" (Bradbury \& McFarlane, 1989, p. 19), pelo aumento da população urbana, da mecanização e da "indústria da diversão em massa" (p. 45) _ impôs nas populações que tradicionalmente habitavam aquele território a necessidade de reestruturar suas diversas "clivagens" e "critérios culturais" (Bauer, 1995), onde ainda predominavam a coleta, a agricultura de subsistência e as tradições comunitárias.

Nas narrativas até agora consideradas, esta "paciente reconstituição", (Bosi, 1987, p.3) onde se reconfiguram e re-significam as experiências vividas, recordar e representar, passam a ser atividades indissociáveis da necessidade de sobrevivência cultural e das atividades de resistência política e econômica nas comunidades remanescentes, uma "defesa da "autenticidade" das experiências particulares e enraizadas num determinado tempo e espaço comunitário contra as forças desterritorializantes, "abstratas", do mercado ou da cultura de massas" (Burity, 2006).

\section{Método}

\section{Participantes}

A fim de que estas questões pudessem ser investigadas, foram reunidas em grupo 23 mulheres, entre 12 e 84 anos, habitantes de 7 comunidades quilombolas: Santana; Córrego Chiado; Nova Vista; Angelim1, Linharinho, São Domingos; Angelim 2. Como já foi dito, a participação das mulheres no estudo foi vinculada àquelas que já se organizam em torno do grupo "natureza em ação". Esse grupo de mulheres se reúne bimensalmente, durante todo um dia. Nestes encontros se trocam receitas de comida e remédios, mudas de plantas, sementes e informações sobre as formas cotidianas de realização das tarefas. $O$ encontro em que a coleta de dados foi realizada foi o terceiro deles. Durante a parte da manhã foi realizado um mutirão, de plantação de mudas na comunidade de Linharinho. Depois do almoço, durante aproximadamente três horas, foi realizado o grupo focal. Todos os três encontros do grupo foram acompanhados pela pesquisadora.

\section{Procedimentos}

Foram propostas ao grupo as seguintes questões: 1) O que significa "ter saúde" para mulheres quilombolas? 2) O que faz "perder a saúde"? 3) Quais eram as doenças de antigamente? 4) Qual são as doenças de hoje? 5) Como se recupera a saúde (física e espiritual)? 6) Qual a relação entre a saúde e a religião? 7) Quais eram as práticas curativas de ontem? 8) Quais são as práticas curativas de hoje?

Nesta proposição foi utilizado o grupo focal como meio de pesquisa, onde se destacam o não direcionamento das respostas às questões propostas pelo pesquisador, o uso de perguntas breves, a adesão voluntária. Segundo Gatti $(2005$,$) a pesquisa com grupos focais tem$ como objetivo primordial de construir, a partir das trocas realizadas no grupo, a captura não apenas de conceitos, mas de crenças, experiências e reações. Fazendo emergir "uma multi- 
plicidade de pontos de vista e processos emocionais, pelo próprio contexto de interação criado, permitindo a captação de significados que, com outros meios, poderiam ser difíceis de se manifestar" (Gatti, 2005, p.9).

Utilizando os pressupostos da análise de conteúdo, as entrevistas foram gravadas, transcritas e, conforme sugestão de Bardin (1979), lidas exaustivamente a fim de que pudessem ir sendo extraídas as "unidades de significação" que compuseram a apreciação do texto.

Estas "unidades temáticas", de "significação" que "se libertam de um texto analisado segundo certos critérios relativos à teoria que serve de guia à leitura" (Bardin, 1979, p. 105), foram delimitadas a partir das respostas que eram espontaneamente dadas às questões iniciais.

\section{Resultados}

Como já foi dito, a questão inicial que motivou o estudo focal com este grupo de muIheres, foi a de que as memórias e representações da saúde funcionariam como um elemento de resistência e cumpririam uma função social, relacionada principalmente às questões identitárias e sua relação frente às formas tecnificadas, globais e indiferenciadas, que chegaram na região a partir da última metade do século XX.

Ilustrando estas questões, as unidades temáticas e sua discussão virão acompanhadas de recortes das falas transcritas. De modo a melhor preservar os sujeitos participantes, estas mesmas falas virão identificadas apenas pela indicação das comunidades e, na medida do possível serão transcritas a partir de sua forma oral originária.

\section{Identidade e práticas de cura e saúde}

No grupo a analisado, muito provavelmente em função de suas características tanto históricas como de movimento social, todas as práticas relacionadas à saúde aparecem de algum modo vinculadas à valoração de sua especificidade identitária. Nas falas isto poderia ser observado na relação entre saúde e trabalho:

A mulher quilombola, ela tem que ter saúde, porque senão ela não agüenta o trabalho. (Nova Vista, 36 anos)

Eu trabalho, eu tiro isso por mim, porque aquele forno ali... Eu que encho forno, eu capino, tem juntar facho, tem fazer beiju, tem torrar farinha, tudo isso, se você não tiver saúde, você vai fazer o que da vida? (Córrego Chiado, 26 anos)

Entre saúde e alimentação:

Uma outra coisa (...) a gente é aquilo que a gente come, essa moçada nova, vê o caruru de veado, ninguém come mais, vê o joão gomes, ninguém come mais, o ora pro nobis, ninguém come mais (Angelim 1, 56 anos)

Eu falo, eu digo, eu sei, tem que aprender a comer aquilo que a terra tá oferecendo (Linharinho, 52 anos).

Entre saúde e conhecimento tradicional:

A nossa saúde precisa resgatar nossas raízes, passar credibilidade, passar fé pra esses novos que tá aí agora (Santana, 49 anos)

Tem que dar valor àquilo que nós plantamos, que este é que é o certo. (São Domingos, 33 anos) 
Na questão da transmissão:

Nós temos que plantar uma semente pra se algum dia nossos filhos quiser reconhecer, dizer: "aqui passou a minha mãe", "esses pé de mato foi passado pelas amigas da minha mãe", tem que ter uma história. (Angelim 2, 22 anos).

\section{Identidade e crença}

Nas questões relativas à crença em sua relação com a formação inter e intragrupais, serão destacadas pelo grupo tanto uma necessidade de resgatar os conhecimentos e a experiência dos ascendentes; quanto uma distância enfática com relação à geração mais nova, que não acreditaria mais nas práticas tradicionais de cura e saúde de seu grupo:

Quantas vezes eu acordava, os olho tavam remelando, mamãe falava: Vai lá no mato pegar sereno, passa na vista pra melhorar. E melhorava. O sereno...bota arruda, bota farinha, bota água e banha. Hoje em dia se você mandar, eu mandar uma filha fazer isso, ela vai falar: Será que isso vai sarar mesmo? Será que ele cura? Acho que vai até cegar. (Linharinho, 52 anos)

Esta descrença é objetivada, no caso da saúde, tanto na substituição das antigas práticas pelos "remédios de farmácia":

É importante também buscar nossas raízes, nossa tradição de vó, de pai e mãe, porque hoje, o que acontece? As ervas tem o mesmo poder como antigamente, só que agora o pessoal ficou tão desacreditado com esse negócio lá da das drogas da farmácia (...) tem as mesmas qualidades, tem o mesmo poder, o problema é a gente buscar nossas raiz, porque hoje não ta mais ninguém mais acreditando. Entendeu? (Santana, 49 anos)

Quanto pelo preconceito que ancora as novas representações das práticas tradicionais de seu grupo:

E tinha também a fé do povo, que hoje em dia não tem. É a fé que cura. Eu acho que isso ai é a pessoa enteder o que é natureza, conhecer um pouco da medicina da vida, não a que o homem criou. Vai chamar ela de macumbeira? Foi um poder que deus deu a ela. É uma coisa que nós podemos usar sem preconceito, antes tinha... é uma coisa do bem. (Chiado, 26 anos)

Hoje tem muito preconceito, principalmente o jovem criado dessa maneira que tá aí, não acredita. (Linharinho, 52 anos).

\section{Discussão}

É notória a contribuição que os estudos sobre a identidade podem oferecer não apenas no campo da psicologia social, como em outras disciplinas comprometidas com o estudo das relações sociais. Em tempos globalizados, torna-se fundamental compreender a influência das referências identitárias na redefinição de "indivíduos, coletividades e territorialidades", (Sawaia, 2002, p. 119) que hoje questionam a "idéia hegemônica de Ocidente" e expressam a "emergência de novas formas de identificação coletiva (...) e de pensamento" (Burity, 2001, p. 1).

Esta compreensão, entretanto, não pode elidir a grande complexidade que ronda o conceito, gerando o que Sawaia (2002) denomina de seus "paradoxos" onde ao mesmo tempo em que resgata a singularidade, resgata com ela "a multiplicidade e o movimento dos fenômenos". Para Souza Santos \& Nunes (2003), além destes paradoxos, este movimento de resgate possuiria ainda uma tensão que lhe é inerente e que constitui o centro mesmo destes movimentos e iniciativas emancipatórias. Tensão quase inevitável, haja vista a condição social e cultural destes processos autorreferentes, necessariamente cotejados a um "ou- 
trem" ou a um "outro", pontos de conflito envolvidos nas "dimensões simbólicas subjacentes a toda relação com a alteridade" (Jodelet, 2002, p. 47), fundamentais para a constituição da própria identidade.

Neste jogo de "metamorfoses" (Souza, 2005), precisarão ser constantemente redefinidos os territórios característicos a uma forma específica de pertencenimento e de atuação. Estas mudanças identitárias responderiam tanto às mudanças contextuais em curso, quanto às sucessivas comparações com outros grupos. Ondas de processos dinâmicos e ininterruptos de construção e desconstrução, que implicam em movimentos de dispersão e coesão (para dentro), de confronto e aliança (para fora) no jogo das relações intergrupais: "Processo múltiplo e ambíguo, que pode ser compreendido como sendo uma das bases tanto para a emergência de conflitos e de violência quanto para ações afirmativas contra a violência." (Souza, 2005, p. 132).

Neste trabalho - que teve como questão geradora a suposição de uma construção identitária, erigida sob as representações de saúde e crença de um grupo de mulheres quilombolas -, esta tensão parece estar no deslocamento de um saber oral, empírico e geracional, para um saber que se descentra e se indiferencia com relação às formas locais de experiência do mundo.

Ainda que restritos, os primeiros resultados encontrados apontam algumas diferenças, para as quilombolas entrevistadas, entre as representações da saúde e das crenças ontem e hoje. Estas diferenças identitárias refletem o que Hall circunscreve como "identidades menos fixas, unificadas" (Hall, 2005, p. 87). Ainda segundo o autor, nos grupos, esta força dispersiva teria efeitos contraditórios: por um lado "tentando recuperar sua pureza interior e recobrir as unidades e certezas que são sentidas como sido perdidas" (p.87). Por outro, aceitando "que as identidades estão sujeitas ao plano da história, da política, da representação e da diferença" (p. 87).

No caso das mulheres quilombolas esta contradição pode ser percebida no interior das suas narrativas, onde, se por um lado transparece um desejo de continuidade perante seus ascendentes; percebe-se também a sensação de uma incapacidade de transmissão destes mesmos valores à geração mais nova, um hiato radical que não havia sido experimentado com relação aos seus ascendentes.

Ainda que a faixa etária de participação no estudo seja larga, entre 22 e 56 anos, é importante ressaltar que se trata de um grupo diferenciado, que está familiarizado com o discurso de organizações não governamentais da Igreja (em particular o da católica), movimentos sindicais, indígenas, do movimento negro urbano, entre outros, o que sugere uma interferência destes vários discursos em sua formação identitária. Interferência que deverá ser retomada e aprofundada em estudos posteriores.

A hipótese inicial_que pressupunha uma função social de resistência às falas e aos recortes mnêmicos dos discursos sobre a saúde e as crenças a ela relacionadas_, se desdobra e complexifica, implicando tanto aspectos cognitivos e sociais; como também sua relação com o processo de constituição de uma alteridade, onde se alinham de modo formador e pedagógico, as idéias de idêntico e de estranho. E de um estranho, importante ressaltar, que também se desdobra em dois: em um outro "amigável", compatível com essas formações identitárias e que é representado pelos atores aliados às lutas quilombolas e um outro realmente "estranho", que surge como elemento dissociador dessa autoimagem construída. 
Pressupor esta dinâmica não significa defender, como já assinalou Souza (2005), a ausência completa de estabilidade nestes processos. No caso desta análise, que pretendeu investigar seus possíveis pontos conflitantes, significa deslocar o ponto de confronto de uma exterioridade alheia e independente, para o interior desta dinâmica psicossocial e pressupor teoricamente esta tensão como elemento chave, tanto na fundação, como na manutenção da identidade.

Essa dinâmica reforça ainda a ideia de Moscovici do universo reificado como uma construção dinâmica, onde as representações, suas transformações e mudanças se comunicam entre si, "se combinam e se separam, introduzem uma quantidade de novos termos e novas práticas no uso cotidiano" (Moscovici, 2004, p. 200). Ainda que estas transformações sejam acompanhadas por uma sensação de perda.

No âmbito da pesquisa realizada e da relação que se estabelece entre o "antes" e a saúde do corpo das novas gerações, é claro o quanto as reminiscências participam da dinâmica representacional e das inúmeras convocações históricas que vão se fazendo, permanecendo socialmente eficazes e atuantes na medida em que apontem, mesmo que de forma não linear, para estes novos parâmetros de designação social do grupo. Inserindo-se em formas ativas de reinterpretação da história e funcionando como determinante na formação do espaço representacional e do "movimento contínuo de mudanças vivas entre gerações" (Rateau \& Rouquette, 2002, p. 52). Oscilando entre a subjugação e a invenção, entre a preservação e a traição, a exatidão e o esquecimento.

\section{Referências}

Arruti, J. M. (2005). Relatório Quilombos do Sapê do Norte - As comunidades negras rurais dos municípios de Conceição da Barra e São Mateus - ES. Rio de Janeiro: Koinonia.

Bardin, L. (1979). Análise de Conteúdo. Lisboa: Edições 70.

Bauer, M. (1995). A popularização da ciência como imunização cultural a função de resistência das Representações Sociais In P. Guareschi \& S. Jovchelovitch. Textos em Representações Sociais (pp. 183-209). Petrópolis: Vozes.

Bhabha, H. K. (2001). O Local da Cultura. B.H.: UFMG.

Bosi, A. (1987). Dialética da colonização. S.P.: Cia das Letras.

Bradbury, M., \& McFarlane, J. (1989). Modernismo: Guia Geral. SP: Cia das Letras.

Burity, J. (2001). Globalização e identidade: desafios do multiculturalismo. Trabalhos para discussão, n. 107. Recuperado de http://www.fundaj.gov.br/.

Burity, J. (2006). Cultura e Identidade nas Políticas de Inclusão Social. In A. Amaral Jr \& J. Burity (Org). Inclusão Social, Identidade e Diferença: Perspectivas Pós-estruturalistas de Análise Social (pp. 39-66). S.P.: Annablume.

Campos, H. (1997). Metalinguagem e outras metas. S.P.: Perspectiva.

Doise, W. (2002). Da psicologia social à psicologia societal. Psicologia: Teoria e Pesquisa, 18(1), 27-35.

Durkheim, E. (1985). As regras do método sociológico. S.P.: Companhia Editora Nacional.

Duveen, G. (2002). A construção da alteridade. In A. Arruda. Representando a alteridade (pp. 83-108). Petrópolis: Vozes.

Gatti, B. A. (2005). Grupo focal na pesquisa em ciências sociais e humanas. Brasília: Líber. 
Hall, S. (2005). A Identidade Cultural na Pós Modernidade. RJ: DP\&A.

Jodelet, D. (2002). A alteridade como produto e processo psicossocial. In A. Arruda. Representando a alteridade (pp. 47-68). Petrópolis: Vozes.

Jovchelovitch, S. (2002). Re(des)cobrindo o outro. Para um entendimento da alteridade na Teoria das Representações Sociais. In A. Arruda. Representando a alteridade (pp. 69-82). Petrópolis: Vozes.

Moscovici, S. (2004). Representações Sociais: Investigações em Psicologia Social. Petrópolis: Vozes.

Novaes, M. (n.d.). História do Espírito Santo. Vitória: Fundo Editorial do ES.

Rateau, P. \& Rouquette, M. L. (2002). Hier est aujourd'hui deux exemples d'actualisations dês sourvenirs. In N. Roussiau \& S. Laurens (Org). La mémoire sociale. Identités et Représentations sociales (pp. 97-106) Rennes: Presses Universitaires de Rennes.

Sá, P. (1993). Representações Sociais: o conceito e o estado atual da teoria. In M. J. Spink (Org). O Conhecimento no Cotidiano: as representações sociais na perspectiva da psicologia social (pp. 19-45). S.P.: Brasiliense.

Santiago, S. (1978). Uma literatura nos trópicos. SP: Perspectiva

Sawaia, B.B. (2002). Identidade_uma ideologia separatista? In B. B. Sawaia (Org.). As artimanhas da exclusão. Análise psicossocial e ética da desigualdade social (pp. 119-128). Petrópolis: Vozes.

Souza Santos, B., \& Nunes, J. A. (2003). Prefácio. In S. Santos (Org). Reconhecer para Libertar. Os caminhos para do cosmopolitismo multicultural (pp. 13-24). R.J.: Civilização Brasileira.

Souza, L. de (2005). Processos de identidade social: da intolerância e violência à utopia solidária. In L. de Souza \& Z. A. Trindade (Orgs.). Simpósio Nacional de Psicologia Social e do Desenvolvimento, 10. Violência e desenvolvimento humano: textos completos (pp. 131-138). Vitória: UFES.

Apresentação: 29/09/2015

Aprovação: 15/03/2016 